\title{
PULSUS GASTROENTEROLOGY NEWS
}

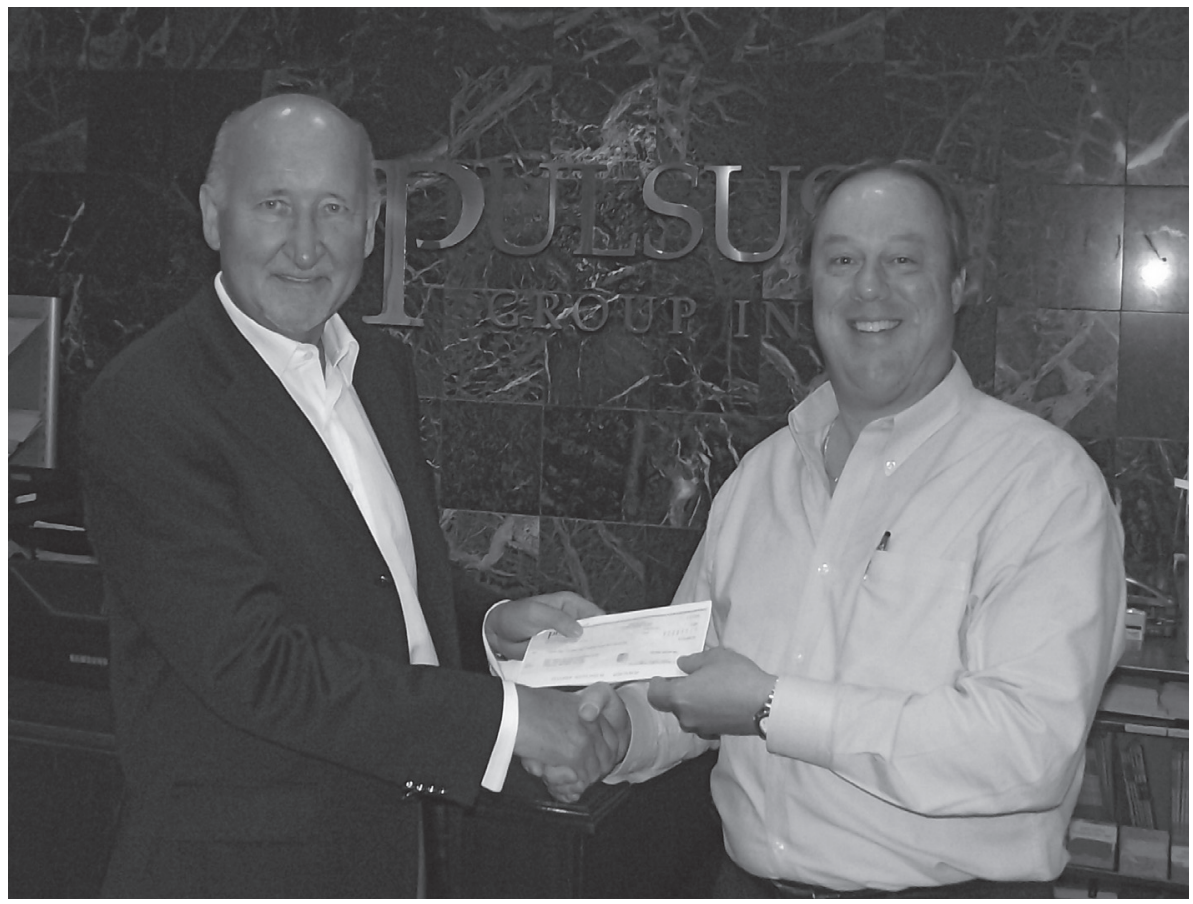

Robert Kalina, Publisher of the Canadian Journal of Gastroenterology (left) presents a cheque to Paul Sinclair, Executive Director of the Canadian Association of Gastroenterology (CAG). The Canadian Journal of Gastroenterology is the official journal of the CAG and, each year, Pulsus Group contributes a percentage of revenues derived from the Journal to the Association for use in future research. 


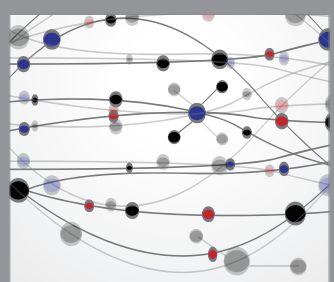

The Scientific World Journal
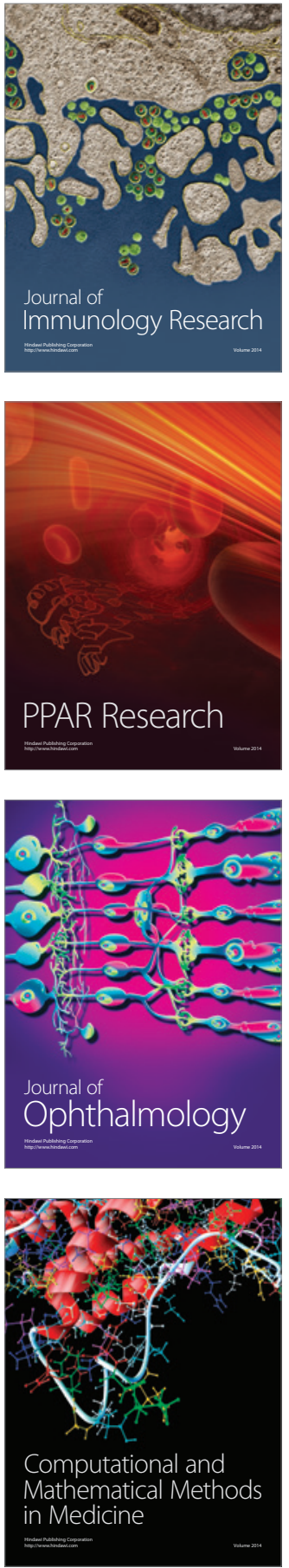

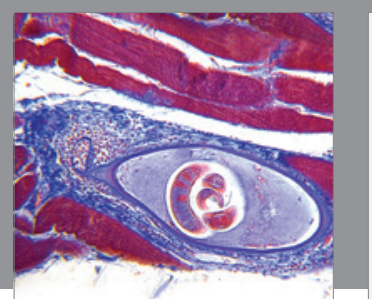

Gastroenterology Research and Practice

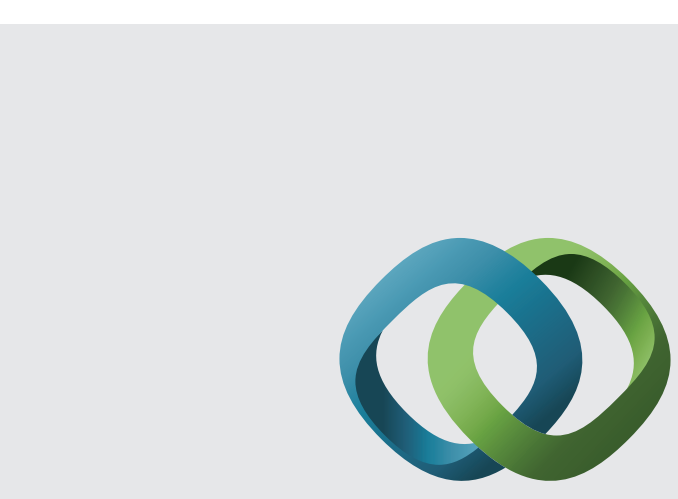

\section{Hindawi}

Submit your manuscripts at

http://www.hindawi.com
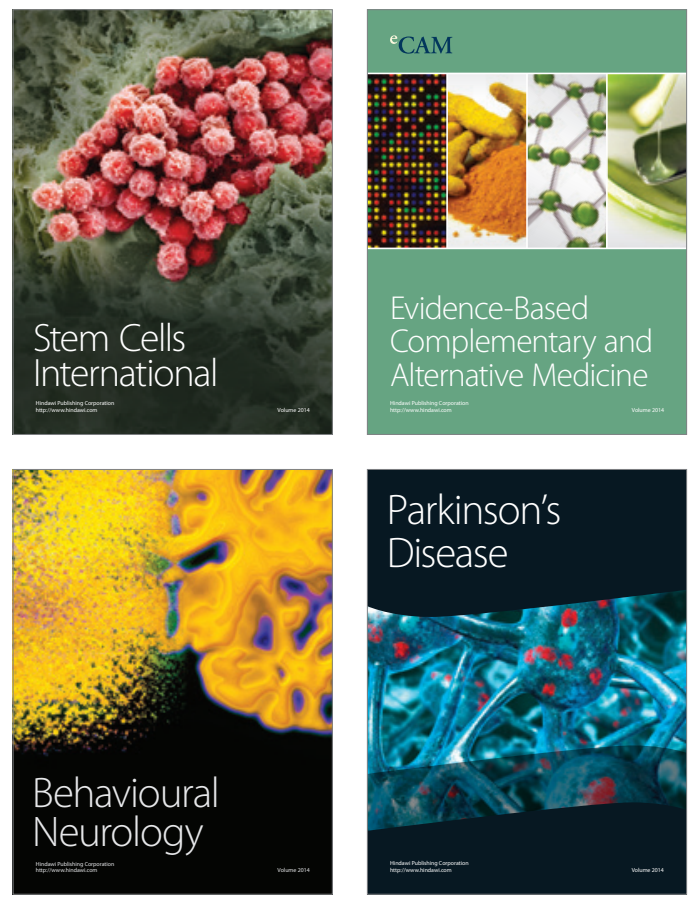
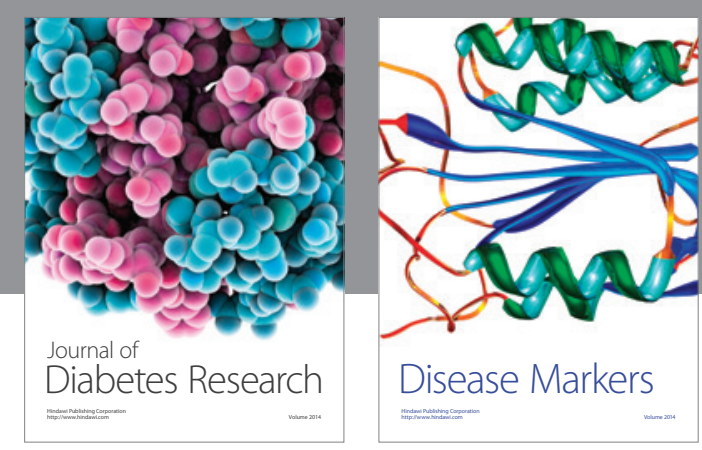

Disease Markers
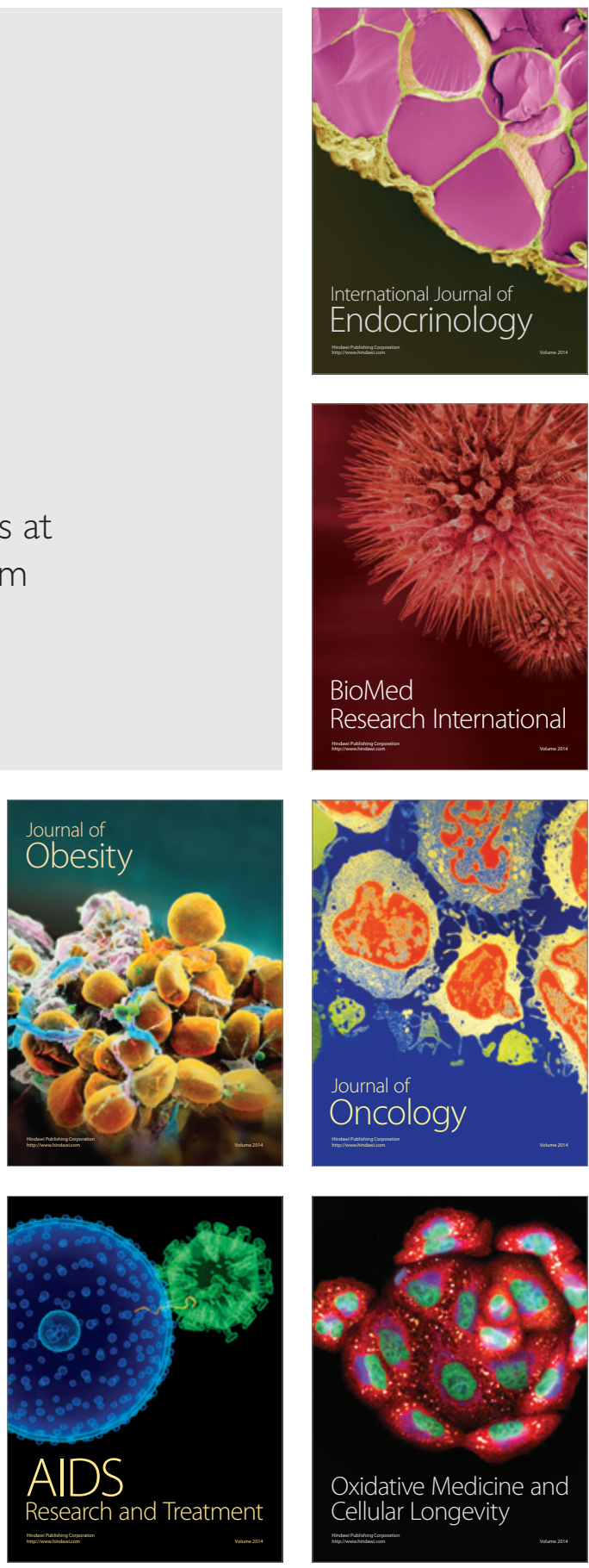